\title{
Clinical judgment in rheumatoid arthritis. III. British rheumatologists' judgments of 'change in response to therapy'
}

\author{
J. R. KIRWAN, ${ }^{1}$ D. M. CHAPUT DE SAINTONGE, ${ }^{2}$ C. R. B. JOYCE ${ }^{3}$ AND \\ H. L. F. CURREY
}

From the ${ }^{1}$ Bone and Joint Research Unit and the ${ }^{2}$ Department of Therapeutics, The London Hospital Medical College, London E1, and ${ }^{3}$ Medical Department, Ciba-Geigy Ltd, Basle 4002, Switzerland

SUMMARY A realistic analysis of the criteria used by rheumatologists in evaluating the progress of patients suffering from rheumatoid arthritis must be based on actual clinical judgments rather than on expressed opinions. A randomly selected $15 \%$ sample of British rheumatologists (48) recorded judgements on the progress of 50 'paper' patients, based on data taken from actual patients participating in clinical trials. The rheumatologists differed markedly in their assessments of the progress of disease, with serious disagreements even when only 'clinically impartant' changes were considered. Some clinicians showed little consistency in their judgments of duplicate cases. Multiple regression analysis of the patient data in relation to the disease assessments provided a model of each clinician's judgment policy. These judgment policy models showed that the differences in clinical assessment were greater than could be explained by the inconsistent application of similar assessment policies, and were a consequence also of differences in the underlying judgment policies themselves. Judgments related more closely to changes in ESR and other process measures than to changes in functional ability.

Key words: Judgment policy models, clinical disagreement, disease outcome, judgment analysis.

Rheumatologists in Britain ${ }^{1}$ and North America $^{2}$ advocate many criteria for assessing changes in the clinical status of patients with rheumatoid arthritis (RA), and most investigators collect large quantities of information about their patients. ${ }^{3} 4$ However, little is known about which criteria are actually used by clinicians in evaluating their patients' progress.

It has proved possible to develop mathematical models of the way rheumatologists judge current disease activity in RA $^{56}$ using 'paper patients'-a convenient technique developed for presenting standard patient data to several doctors on different occasions $^{17}$ - and judgment analysis - a form of multivariate analysis of the information on which decisions are based. ${ }^{589}$ These models of judgment policy differed markedly not only from each other

Accepted for publication 11 April 1984.

Correspondence to Dr J. R. Kirwan, Bone and Joint Research Unit, London Hospital Medical College, Arthritis and Rheumatism Council Building, 25-29 Ashfield Street, London E1 1AD. but also from the policies clinicians claimed to be using. ${ }^{5}$

A realistic view of the way physicians assess patients' response to therapy must therefore be based on actual judgments rather than expressed opinions. Such an analysis, by making underlying judgment policies more explicit, may clarify differences in the assessment of particular patients and would allow rational discussion of their importance and implications. ${ }^{9}$ An understanding of judgment policies is also necessary for the design of soundly based clinical investigations in RA. ${ }^{10}$ We therefore decided to discover how British rheumatologists judge the success or failure of treatment.

\section{Material and methods}

A representative sample of British rheumatologists was asked to assess improvement or deterioration in 50 paper patients, and policy models were calculated (for each rheumatologist) from these judgments. 
The assessments and judgment policy models were compared in several ways.

\section{SAMPLE SELECTION}

Three hundred and four members of the Heberden Society were identified as practising rheumatologists at consultant or senior registrar grade. A sample of 56 of these was chosen by random number generation, and the current appointment, geographical location, and year of qualification of each member obtained from the Medical Directory. ${ }^{11}$ To estimate the extent to which sample members were engaged in clinical research five English language rheumatology journals (Annals of the Rheumatic Diseases, Arthritis and Rheumatism, British Journal of Rheumatology, Journal of Rheumatology, and Scandinavian Journal of Rheumatology) were reviewed for reports (regardless of quality) of clinical investigations and trials during 1978-81 and the authorship of sample members noted. Sample members were contacted by post with a letter of explanation inviting them to participate in the study, a form on which to indicate their opinions about the importance of the clinical variables used to describe the paper patients (results not included in this report), a list of the units and normal ranges for each clinical variable, a set of 50 paper patients (identical for each sample member), and a return envelope. Up to two further contacts (by letter or telephone) were made to encourage completion of the survey.

\section{CASE SELECTION}

(i) Selection of clinical variables. Table 1 shows the clinical variables included in the patient data sets circulated. These were chosen either because they scored high marks in a previous survey of rheumatologists' options ${ }^{1}$ or because they are frequently reported in drug trials.

(ii) Selection of values for the clinical variables. Real patient data were gathered from the following sources: (a) Thirty patients who had been entered into clinical trials (and had taken gold, Dpenicillamine, or aspirin). Information included aspirin consumption, erythrocyte sedimentation rate (ESR), haemoglobin, morning stiffness, grip strength, and articular index. Measurements of pain and functional capacity were used after rescaling. Erosion counts and overall patient assessment had not been recorded. (b) The Empire Rheumatism Council gold trial ${ }^{12}$ was used to assign a value for erosions to each patient. Patients were assigned a value generated randomly but within the distributions quoted in the trial report for before and after treatment. (c) The same trial ${ }^{12}$ was used to calculate the patient's global assessment in a similar manner to the erosion counts. The estimate of ' $\%$ fit' used in the trial was converted to the scale used in the paper patients $(100 \%=0 ; 75 \%=1 ; 25 \%=3 ; 1 \%=4)$. Twenty of the 30 cases were randomly selected to be presented in duplicate and these were arranged so that duplicate cases did not occur close together.

\section{DATA PRESENTATION}

Fig. 1 shows a typical set of data. Judgments of change in the patient's condition were indicated on the $11 \mathrm{~cm}$ visual analogue scale (VAS). These were scored in $\mathrm{mm}$ from the 'no change' mark. Improvement received a positive score (maximum +55$)$ and deterioration a negative score (maximum -55). A second judgement about the 'clinical importance' of any observed change was also recorded (a definition of clinical importance was not given). Clinical importance scores were -1 (clinically important deterioration), 0 (not clinically important), or +1 (clinically important improvement).

\section{ANALYSIS}

Judgments were analysed as previously described. ${ }^{5}$ In brief, all possible subset regression analysis ${ }^{13}$ was used, the untransformed VAS judgment being taken as the dependent variable and the 10 initial values

Table 1 Clinical variables included in patient data

\begin{tabular}{ll}
\hline Clinical variables & Range (× step size) \\
\hline Aspirin (or any other non-steroidal drug) usage (ASP) & $0-16 \times 1$ per day \\
ESR & $10-100 \times 1 \mathrm{~mm} / \mathrm{h}$ \\
Haemoglobin (Hb) & $8-15 \times 0 \cdot 1 \mathrm{~g} / \mathrm{dl}$ \\
Number of erosions on hand $x$-rays (EROS) & $0-24 \times 1$ \\
Patient's assessment of morning stiffness (EMS) & $0,5,15,30-360 \times 30 \mathrm{~min}$ \\
Patient's global assessment of current disease activity (GLOB) & $0-4 \times 1$ (0= lowest possible, $4=\mathrm{highest}$ possible) \\
Patient's pain score (PAIN) & $0-4 \times 1$ (0) none, $4=$ worst possible) \\
Physician's assessment of functional capacity (FC) & $1-4 \times 1$ (1 = independent, $4=$ totally dependent) \\
Physician's measurement of grip strength (GRIP) & $75-450 \times 5 \mathrm{mmHg}$ \\
Physician's measurement of Ritchie articular index (AI) & $0-78 \times 1$
\end{tabular}

Values were recorded before and after one year of treatment with an unspecified 'second-line' agent. 
Clinical Judgement in Fhermatolopy

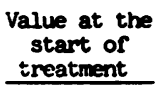

Aspirin (or equivalent

drug) usage

ESR

Haemoglobin

Number of erosions

on hand X-rays

Morning stifmess

Patient's global assessment

Pain score

Functional capacity

Grip strength

Articular Index
8

42

10.5

6

60

2

3

1

88

25

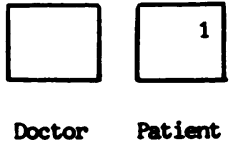

Value arter one year

\section{7}

4

10.0

9

. 0

1

2

1

208

6
Fig. 1 A paper patient used in the survey.

Indicate the degree of change in the patient's condition by drawing a line at the appropriate point on the scale below.

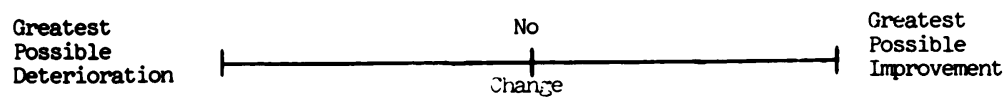

Indicate with a TICK if you think the change in the patient's condition is CLINICALLY IMPORTANT or a cross if you think it is NOT CLINICALLY IMPORTANT.

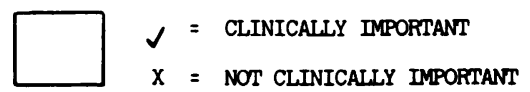

and 10 changes in value of each clinical variable as the independent variables (giving 20 cues in all). ${ }^{14}$ The computer program employed ${ }^{13}$ requires the definition of a 'penalty' to aid in the derivation of regression equations, and this was set at $4 .^{14}$ The importance of clinical variables included in the judgment policy model is expressed as their relative contribution to $R^{2}\left(r c R^{2}\right)$, the variance in the judgments of an individual judge that can be accounted for by his linear regression judgment policy model. ${ }^{5}$

Consistency of judgments was assessed by the Spearman rank correlation coefficient for the dupli- cate cases in each data set. Rheumatologists' demographic data and judgment policy models were each grouped together by cluster analysis. ${ }^{15}$ Because cluster analysis is an imprecise technique, rheumatologists and policy models grouped in this way have been compared in general rather than in detail. Differences between clusters were tested using $\chi^{2}$ with Yates's correction.

\section{Results}

Complete tabulations of all results are available from the authors on request. For the sake of clarity 
and brevity only summary tables and figures are presented here.

Response rate. Completed forms were returned by 48 rheumatologists ( $86 \%$ response). The distribution of respondents did not differ from that of the initial sample for any of the demographic data collected (type of appointment, geographical location, year of qualification, or number of published papers).

Judgments. There were major differences of judgment between the respondents for many patients. Typical examples are illustrated in Fig. 2. The mean response for each patients is shown in Table 2.

Judgments of clinical importance. It was expected that the requirement to classify changes in disease activity as clinically important or not important

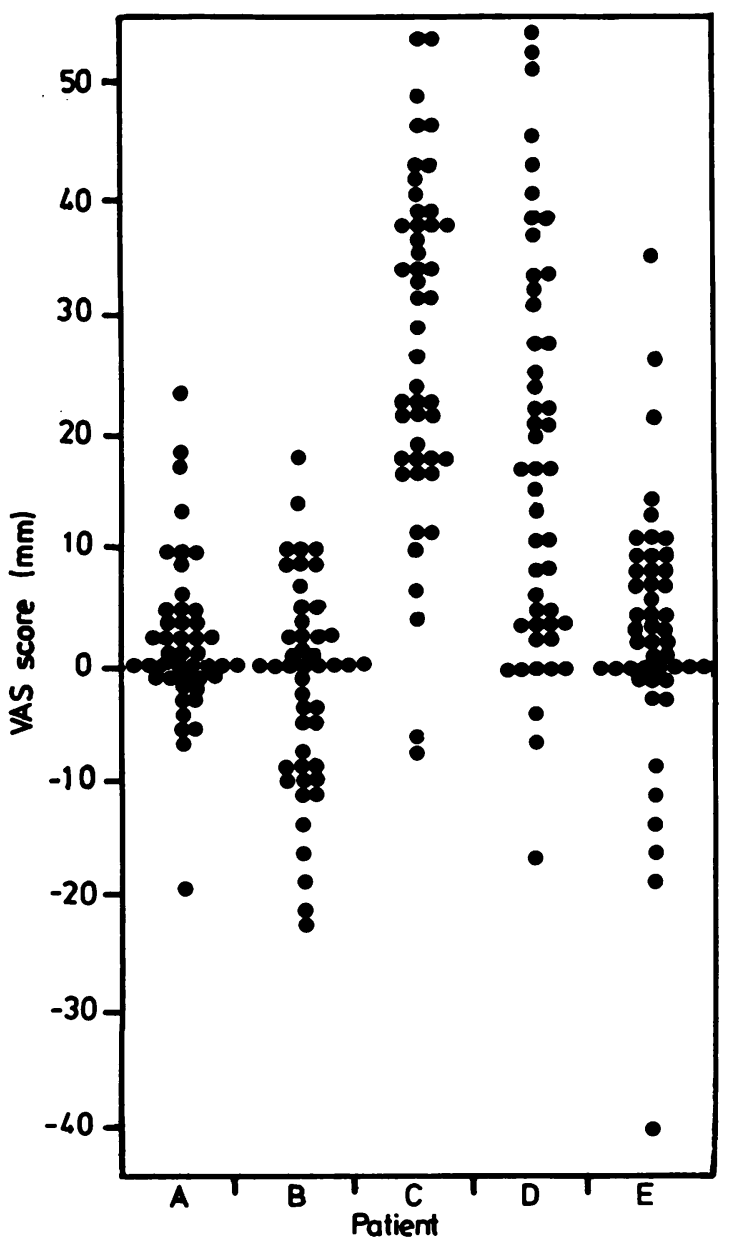

Fig. 2 Distribution of VAS scores for five representative patients.
Table 2 Mean and standard deviation of judgements $(n=48)$

\begin{tabular}{|c|c|c|c|c|c|}
\hline Patient & Mean & $\begin{array}{l}\text { Standard } \\
\text { deviation }\end{array}$ & Patient & Mean & $\begin{array}{l}\text { Standard } \\
\text { deviation }\end{array}$ \\
\hline 1 & 28 & 14 & 26 & 6 & 15 \\
\hline 2 & -2 & 9 & 27 & -2 & 10 \\
\hline 3 & 1 & 7 & 28 & 1 & 7 \\
\hline 4 & 42 & 12 & 29 & 7 & 11 \\
\hline 5 & 18 & 12 & 30 & 3 & 11 \\
\hline 6 & 6 & 7 & 31 & 24 & 13 \\
\hline 7 & 5 & 7 & 32 & 24 & 14 \\
\hline 8 & 7 & 11 & 33 & 6 & 8 \\
\hline 9 & -5 & 6 & 34 & 14 & 13 \\
\hline 10 & 12 & 15 & 35 & 17 & 14 \\
\hline 11 & 14 & 13 & 36 & 5 & 7 \\
\hline 12 & 13 & 14 & 37 & 7 & 13 \\
\hline 13 & 2 & 7 & 38 & 5 & 8 \\
\hline 14 & 18 & 14 & 39 & 6 & 9 \\
\hline 15 & 4 & 6 & 40 & -11 & 13 \\
\hline 16 & 40 & 15 & 41 & 19 & 15 \\
\hline 17 & 19 & 13 & 42 & 5 & 7 \\
\hline 18 & 5 & 7 & 43 & 12 & 13 \\
\hline 19 & 1 & 8 & 44 & 16 & 15 \\
\hline 20 & 5 & 12 & 45 & 7 & 11 \\
\hline 21 & 18 & 17 & 46 & 7 & 15 \\
\hline 22 & 5 & 6 & 47 & 6 & 10 \\
\hline 23 & 5 & 6 & 48 & 17 & 15 \\
\hline 24 & 1 & 6 & 49 & 3 & 10 \\
\hline 25 & -13 & 11 & 50 & 9 & 10 \\
\hline
\end{tabular}

would increase the degree of agreement between clinicians. However, Table 3 illustrated that, even applying this criterion, there remains considerable disagreement. For some patients (e.g. No 4) there is a broad consensus, but for others (e.g. No 37) agreement occurs little more than by chance. For no patient were all rheumatologists in agreement.

Relationship between amount of change and clinical importance of change. There was a broad correspondence between the mean VAS score for each patient and the proportion of the respondents considering the change clinically important, but there was a large overlap between the categories. Fig. 3 shows this graphically, and it can be seen that, although negative VAS scores are likely to occur in patients classified by most respondents as showing a clinically important deterioration and positive scores occur in those usually classified as improving, as might be expected, there is a large overlap in the curves suggesting that any consensus or 'average' assessment of change will conceal considerable disagreement about clinical importance.

$V A S$ consistency. A measure of the consistency of each rheumatologist's judgments is provided by the correlation between judgments of duplicate cases (Fig. 4). Although some were highly consistent, as shown by a high correlation, others were not. Indeed, those of the two physicians with $r<0.4$ did 
Table 3 Judgments of the clinical importance of any change in disease by 48 rheumatologists

\begin{tabular}{|c|c|c|c|c|c|c|c|c|c|c|c|}
\hline \multirow{2}{*}{$\begin{array}{l}\text { Patient } \\
\text { No }\end{array}$} & \multicolumn{3}{|c|}{ Judgment* } & \multirow{2}{*}{$\begin{array}{l}\text { Patient } \\
\text { No }\end{array}$} & \multicolumn{3}{|c|}{ Judgment* } & \multirow{2}{*}{$\begin{array}{l}\text { Patient } \\
\text { No }\end{array}$} & \multicolumn{3}{|c|}{ Judgment ${ }^{*}$} \\
\hline & -1 & 0 & +1 & & -1 & 0 & +1 & & -1 & 0 & $+I$ \\
\hline 1 & 1 & 2 & 45 & 18 & 2 & 34 & 12 & 34 & 0 & 23 & 25 \\
\hline 2 & 6 & 35 & 7 & 19 & 4 & 36 & 8 & 35 & 1 & 14 & 33 \\
\hline 3 & 4 & 41 & 3 & 20 & 6 & 23 & 19 & 36 & 0 & 35 & 13 \\
\hline 4 & 0 & 1 & 47 & 21 & 1 & 18 & 29 & 37 & 7 & 20 & 21 \\
\hline 5 & 0 & 16 & 32 & 22 & 0 & 40 & 18 & 38 & 2 & 32 & 14 \\
\hline 6 & 1 & 33 & 14 & 23 & 0 & 37 & 11 & 39 & 1 & 30 & 17 \\
\hline 7 & 3 & 32 & 13 & 24 & 5 & 39 & 4 & 40 & 34 & 13 & 1 \\
\hline 8 & 2 & 25 & 21 & 25 & 33 & 14 & 1 & 41 & 1 & 12 & 35 \\
\hline 9 & 11 & 37 & 0 & 26 & 8 & 18 & 22 & 42 & 1 & 31 & 16 \\
\hline 10 & 2 & 21 & 25 & 27 & 12 & 31 & 5 & 43 & 0 & 26 & 22 \\
\hline 11 & 2 & 14 & 32 & 28 & 6 & 34 & 8 & 44 & 2 & 12 & 34 \\
\hline 12 & 2 & 15 & 31 & 29 & 1 & 33 & 14 & 45 & 0 & 36 & 12 \\
\hline 13 & 1 & 41 & 6 & 30 & 5 & 30 & 13 & 46 & 7 & 14 & 27 \\
\hline 14 & 0 & 14 & 34 & 31 & 0 & 7 & 41 & 47 & 4 & 26 & 18 \\
\hline 15 & 0 & 39 & 9 & 32 & 0 & 7 & 41 & 48 & 0 & 19 & 29 \\
\hline 16 & 0 & 3 & 45 & 33 & 0 & 33 & 15 & 49 & 4 & 36 & 8 \\
\hline 17 & 0 & 13 & 35 & & & & & 50 & 1 & 27 & 20 \\
\hline
\end{tabular}

${ }^{*}-1=$ clinically important deterioration; $0=$ no clinically important change; $+1=$ clinically important inprovement.

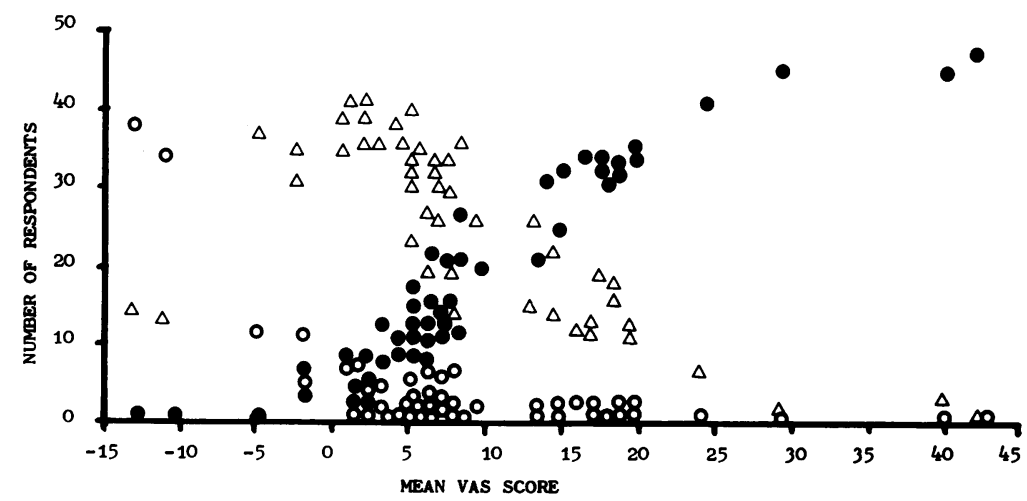

Fig. 3 VAS scores and clinical importance of changes.

Relationship between mean VAS score for each patient (horizontal axis) and number of respondents classifying changes as clinically important improvement (O) or deterioration $(\mathrm{O})$, or not clinically important $(\triangle)$.

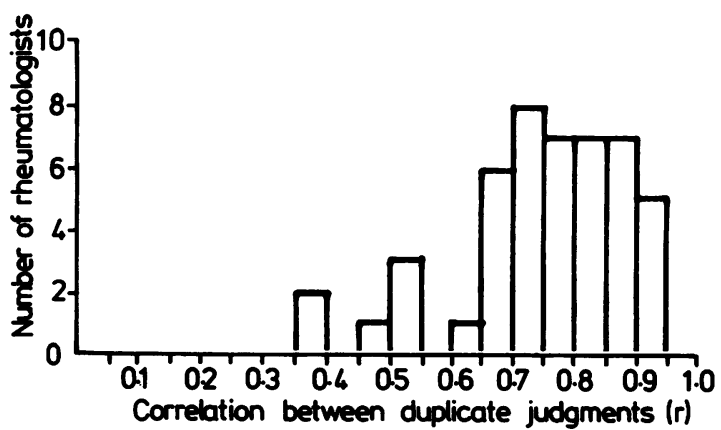

Fig. 4 Variations in correlation between duplicate judgments. not reach the conventional level of statistical significance $(\mathrm{p}<0.05)$.

Clinical judgment analysis. The relative importance of each clinical variable in the judgment policy models of the respondents is illustrated in Table 4. The variance in judgments explained by each model ranges from $35 \%$ to $97 \%$, and for 36 models $\mathrm{R}$ was greater than 0.7 , indicating that $50 \%$ or more of the variance was satisfactorily accounted for by the model. Twenty-two of the 48 had an $R$ of 0.8 or more, indicating that the models accounted for at least two-thirds of the variance. The mean relative contribution of each clinical variable for all respondents taken together is given in the last row of Table 4 . 


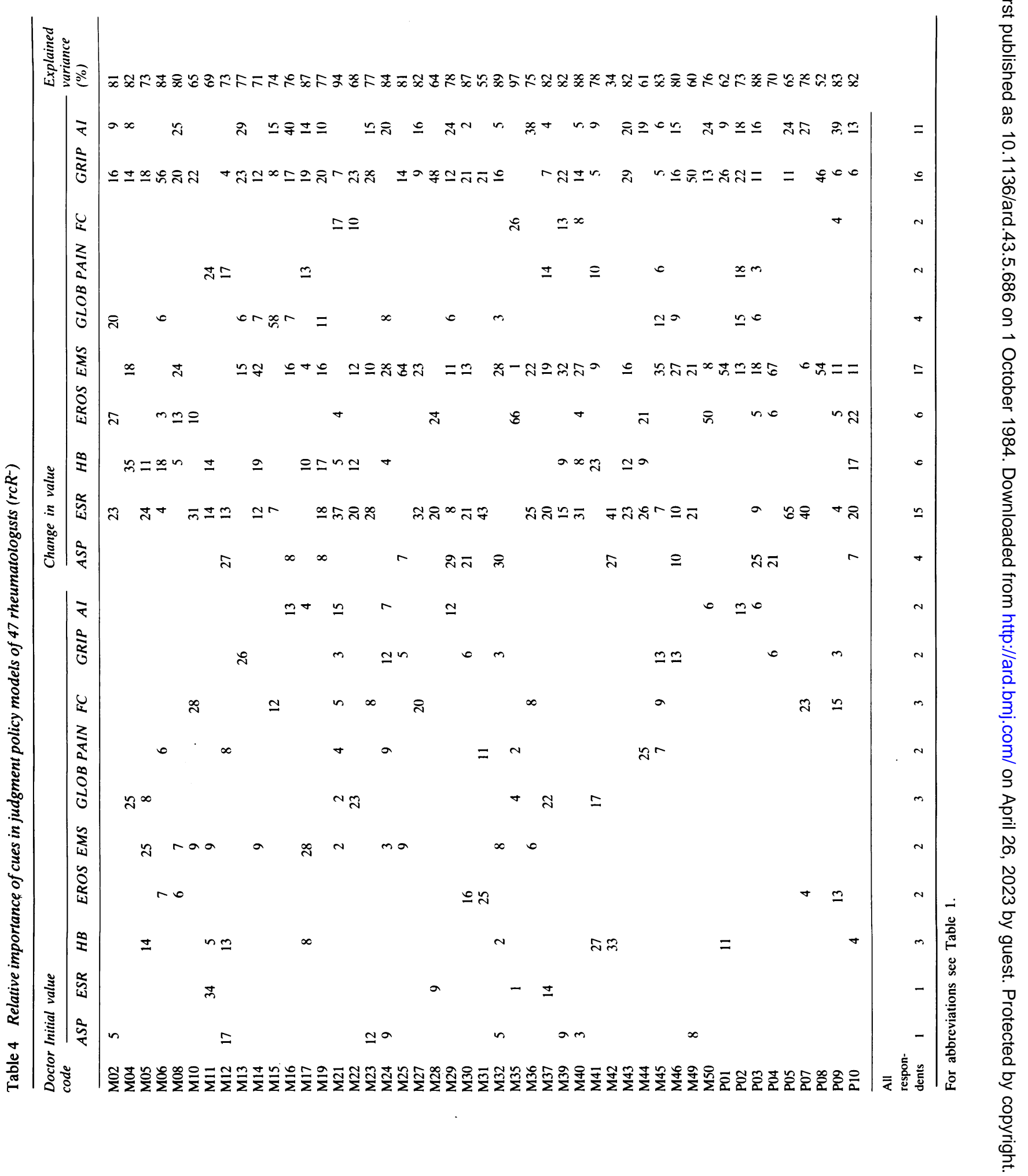


Table 5 Demographic cluster analysis

\begin{tabular}{|c|c|c|c|c|c|c|c|c|c|}
\hline \multirow{3}{*}{$\begin{array}{l}\text { Cluster } \\
\text { name } \\
\mathrm{D} 1\end{array}$} & \multirow{3}{*}{$\begin{array}{l}\begin{array}{l}\text { Number in } \\
\text { cluster }\end{array} \\
12\end{array}$} & \multirow{3}{*}{$\begin{array}{l}\text { Qualification } \\
\text { year }\end{array}$} & \multicolumn{2}{|c|}{ Demographic characteristics } & \multirow{3}{*}{$\begin{array}{l}\text { Published } \\
\text { papers }\end{array}$} & \multirow{2}{*}{\multicolumn{4}{|c|}{$\begin{array}{l}\text { Four major clinical variables in } \\
\text { mean policy model of cluster }\end{array}$}} \\
\hline & & & \multirow{2}{*}{$\begin{array}{l}\text { Geography } \\
\begin{array}{l}\text { Midlands \& } \\
\text { SE England } \\
\text { (not cities) }\end{array}\end{array}$} & \multirow{2}{*}{$\begin{array}{l}\text { Appointment * } \\
\text { DGH1 } 5 \\
\text { DGH2 } 6\end{array}$} & & & & & \\
\hline & & & & & & GRIP & ESR & EMS & GLOBAL \\
\hline $\mathrm{D} 2$ & 13 & NS & $\begin{array}{l}\text { Cities in } \\
\text { SE England }\end{array}$ & $\begin{array}{ll}\text { T } & 7 \\
\text { DGH1 } & 3 \\
\text { DGH2 } & 3\end{array}$ & NS & GRIP & ESR & EMS & $\mathrm{AI}$ \\
\hline D3 & 10 & NS & $\begin{array}{l}\text { Cities in } \\
\text { North of } \\
\text { England \& } \\
\text { Scotland }\end{array}$ & $\begin{array}{ll}\text { A } & 2 \\
\text { T } & 6 \\
\text { DGH2 } & 2\end{array}$ & NS & GRIP & ESR & ASP & $\mathrm{Al}$ \\
\hline
\end{tabular}

NS = not significantly different.

* DGH1 (2) = district general hospital with one (more than one) rheumatologist; $T=$ teaching hospital; $\mathrm{A}=$ Academic; $\mathrm{O}=$ other.

Demographic analysis of policies. Three major groups of rheumatologists were suggested by cluster analysis of the respondents' demographic data. These differed significantly $(p<0.001)$, as shown Table 5. The four major clinical variables in the mean policy models of each of these groups are also shown. Although each model includes grip strength and ESR, they differ in the inclusion of early morning stiffness, patient's global assessment, articular index, and aspirin consumption. Separate analysis of those who were authors of any papers in the journals reviewed compared with those who published none showed no significant differences in the mean policy models of each group. Similarly, there were no differences in consistency $(r)$ between these two groups, nor in the ability of the regression equations to model judgments $\left(R^{2}\right)$.

Cluster analysis of policy models. Cluster analysis was performed on all the policy models taken together in order to seek possible natural groupings rather than superimposed clusters, such as those defined by the respondents' demographic data. Those clinical variables contributing $10 \%$ or more to the mean policy model of each of the three clusters which emerged are shown in Table 6. The differences between the models $(p<0.001)$ are concen-

Table 6 Main contributing variable for policy model clusters

\begin{tabular}{llllll}
\hline $\begin{array}{l}\text { Cluster } \\
\text { name }\end{array}$ & $\begin{array}{l}\text { Number } \\
\text { in cluster }\end{array}$ & \multicolumn{4}{l}{$\begin{array}{l}\text { Relative contribution to } \\
\text { variables }\end{array}$} \\
\cline { 3 - 6 } & & ESR & EMS & GRIP clinical & AI \\
\hline A & 12 & 15 & 21 & 18 & 12 \\
B & 12 & 13 & 26 & 0 & 19 \\
C & 9 & 16 & 26 & 24 & 0 \\
\hline
\end{tabular}

trated in the variables grip strength and articular index. The doctors making up these clusters do not coincide with those defined by demographic data.

\section{Discussion}

British rheumatologists show marked disagreement not only on their opinions about the way changes in disease activity in RA should be assessed ${ }^{1}$ but also, as shown in this report, in their actual judgments of disease progress. Furthermore, these differences are present in models constructed to clarify the underlying pattern of judgments made by the clinicians.

It seems reasonable to assume that the results of this survey are generally applicable because it included a large randomly selected proportion of British rheumatologists $(15 \%)$, there was a high response rate $(86 \%)$, and the characteristics of the respondents closely mirrored those of the initial sample. Rheumatologists in other countries might respond differently.

Several considerations governed the selection of patient data to be included in the survey. Although the number of clinical variables employed by a particular clinician may be small, ${ }^{56}$ the expressed policies of clinicians in general cover a wide range of variables. ${ }^{12}$ If more than about 20 variables are included, the complexity of the computational procedures becomes unacceptable. In addition there is considerable evidence that the human mind is unable to deal with more than five to nine variables simultaneously ${ }^{16}$ If too few are included the chance of omitting criteria which are important to some clinicians would be unacceptably high. The before and after treatment values of 10 clinical variables were therefore chosen and, in the event, provided 
sufficient data to derive judgment policy models that explained a high proportion of the variance. The values used were taken as far as possible from those of real patients who had undergone treatment for their arthritis, thus reflecting the intercorrelations found in real life between these variables, and were representative of changes likely to be found in clinical practice. Presenting clinical information as 'paper patients' has previously been shown to elicit judgments very similar to those made when assessing their real life equivalents. ${ }^{17}$

Rheumatologists' judgments of disease progress proved to be extremely variable. This variability might have been related to differences in the use of a VAS. However, though judgments for 'clinical importance' of any changes used a scale of only three categories, thus providing a much more restricted range of interpretations, the large differences in judgments remained. In addition the policy models were calculated independently for each physician and thus related specifically to his or her own use of the VAS, independently of the way in which the scale was used by others. Nevertheless these models also showed a wide variation between rheumatologists.

Cluster analysis was used to group respondents according to their demographic details or directly in relation to their policy models. The resultant groupings, though tested for significance after they were identified, are considered in broad terms only in order to avoid overinterpretation of complex statistical techniques. Difference in policy models bore some relationship to demographic characteristics. While grip strength and ESR were common to all three groups identified, a combination of geography and appointment separated those who relate their judgments to 'patient centred' assessments (EMS, patients global assessment) from those who use more 'doctor oriented' assessments (NSAID comsumption, articular index). The former group tend to hold appointments in district general hospitals in provincial towns, while the latter includes a high proportion of academic and teaching hospital appointees.

When groupings were sought within all the policy models taken together, three slightly different clusters emerged (Table 6). All share the ESR as an important variable, and it has been suggested ${ }^{17-20}$ that this may be related to long-term outcome in RA, particularly the development of radiographic erosions. In contrast, functional capacity does not appear in any of the cluster policies and was present with a contribution of $10 \%$ or more in the policy models of only four doctors. This finding may reflect a recognised preoccupation with measures of disease process rather than disease outcome. ${ }^{2610}$
The major clinical disagreements identified in this report are greater than could be explained by the inconsistent application of similar approaches to assessment by different clinicians. They are also a consequence of differences in the clinicians' underlying judgment policies. The explicit definition of policy models should help to reduce inconsistency in their application and thus improve agreement. ${ }^{81}$ In a preliminary investigation the feedback supplied by policy models succeeded in improving agreement between two rheumatologists when diagnosing rheumatoid arthritis. ${ }^{6}$ Improving clinical agreement should enhance the quality of patient care and increase the power of those clinical trials and other investigations which depend on clinical judgment ${ }^{6}$ that is, most if indeed not all.

Dr John Kirwan was supported by the Arthritis and Rheumatism Council for Research. We thank Drs J. S. Dixon and H. A. Bird, Clinical Pharmacology Unit (Rheumatism Research), Royal Bath Hospital, Harrogate, for supplying some of the patient data.

\section{References}

1 Kirwan J R, Chaput de Saintonge D M, Joyce C R B. Currey H L F. Clinical judgement in rheumatoid arthritis. I. Rheumatologists' opinions and the development of 'paper patients'. Ann Rheum Dis 1983; 42: 644-7.

2 Conference on outcome measures in rheumatological clinical trials, Hamilton, Ontario, Canada, 7 and 8 December 1981. $J$ Rheumatol 1982; 9: 753-806.

3 Multicentre Study Group. Levamisole in rheumatoid arthritis. Ann Rheum Dis 1982; 41: 159-63.

4 Dixon J S, Pickup M E, Lowe J R, Hallett C, Lee M R, Wright $V$. Discriminatory indices of response of patients with rheumatoid arthritis treated with D-penicillamine. Ann Rheum Dis 1980; 39: 301-11.

5 Kirwan J R, Chaput de Saintonge D M, Joyce C R B, Currey H L F. Clinical judgment in rheumatoid arthritis. II. Judging current disease activity in clinical practice. Ann Rheum Dis 1983; 42: 648-51.

6 Kirwan J R, Chaput de Saintonge D M, Joyce C R B. Currey H L F. Clinical judgment analysis-practical application in rheumatoid arthritis. In: Advances in assessing rheumatoid arthritis. Br J Rheumatol 1983; 22 (suppl): 18-23.

7 Kirwan J R, Bellamy N, Condon H, Buchanan W W, Barnes C G. An international comparison of judgement in rheumatoid arthritis. J Rheumatol 1983; 10: 901-5.

.8 Hammond K R, Stewart T R, Brehmer B, Steinman D O. Social judgement theory. In: Kaplan M F, Schwartz S, eds. Human judgment and decision processes. New York: Academic Press, 1975.

9 Joyce C R B, Hammond K R. Improving clinical judgement. In: Advances in assessing rheumatoid arthritis. $B r J$ Rheumatol 1983; 22 (suppl): 14-7.

10 Kirwan J R, Currey H L F. Rheumatoid arthritis: disease modifying anti-rheumatic drugs. In: Klippel J H, Decker J L, eds. Clin Rheum Dis 1983; 9: 581-99.

11 The Medical Directory. London: Churchill Livingstone, 1982.

12 Empire Rheumatism Council. Gold therapy in rheumatoid arthritis: final report of a multi-centre controlled trial. Ann Rheum Dis 1961; 20: 315-33.

13 Frane J W. All possible subsets regression. In: Dixon W J Brown M B, Engleman L, eds. Biomedical computer programs, $P$-series. Berkeley: University of California Press, 1981. 
14 Kirwan J R. M D Thesis, University of London.

15 Engleman L. Cluster analysis of cases. In: Dixon W J. Brown M B. Engleman L, eds. Biomedical computer programs, P-series. Berkeley: University of California Press, 1981.

16 Miller G A. The magical number seven, plus or minus two: some limits on our capacity for processing information. Psychol Rev 1956; 63: 81-97.

17 McConkey B, Davies P. Crockson R A, et al. Effects of gold. dapsone, and prednisolone on serum C-reactive protein and haptoglobin and the erythrocyte sedimentation rate in rheumatoid arthritis. Ann Rheum Dis 1979; 38: 141-4.
18 Wright V. Amos R. Do drugs change the course of rheumatoid arthritis? Br Med J 1980); 280: 964-6.

19 Sharp J P. Lidsky M D. Duffy J. Clinical responses during gold therapy for rheumatoid arthritis-change in synovitis, radiologically detectable erosive lesions, serum proteins and serologic abnormalities. Arthritis Rheum 1982; 25: 540-9.

20 Grindulis K A. McConkey B. Do drugs alter the course of rheumatoid arthritis? In: Wright V. ed. Topical revien's in rheumatic disorders. Bristol: Wright. 1982: 2: 97-1.32.

21 Hammond K R. Summers D A. Cognitive control. Psychol Rev 1972; 79: $58-67$. 